\title{
Some properties of the olfactory system of man'
}

HERBERT STONE ANO GORDON PRYOR

DEPARTMENT OF BIOBEHAVIORAL SCIENCES, STANFORD RESEARCH INSTITUTE

Preliminary investigations into the effects of a $12-h \mathrm{di}$ urnal variation suggested there was a 10-fold decrease in odor sensitivity from morning to evening. For a selected group of odorants (methyl, $t$-butyl, and phenyl isonitrile), the difference between detection and recognition thresholds in general was found to be 10-fold; however, for some Ss the difference was less. When $S$ s were blindfolded, no changes in odor sensitivity were noted. Similarly, imposing an auditory stress on the test situation did not significantly alter odor sensitivity in either experienced or naive $S$ s.

While conducting a series of investigations into the olfactory response of man, we had an opportunity to observe the effects of several physical variables on odor sensitivity. We were impressed by the variety of conditions that could be imposed upon an individual in a laboratory situation without grossly altering sensitivity (i.e., producing less than a 10-fold change in sensitivity). Observation of current literature had revealed little or no quantitative data on the differences between detection and recognition thresholds, and on such conditions as diurnal variation, the effect of blindfolding $S$, and imposing an auditory stress on $S$ while testing. Therefore we were prompted to report the results of some of our preliminary investigations pertaining to these conditions.

\section{Subjects}

A panel of six Ss (all males) was selected on the basis of their willingness to participate, availability, and absence of any gross olfactory aberrations as determined by interview with each $\mathrm{S}$ prior to testing. These Ss had been used for other experiments during the previous six months and are considered experienced in odor testing (Stone, Pryor, \& Colwell, 1967). Their ages ranged from 22 to 32 years; all are employees of the Stanford Research Institute. Ss were instructed to refrain from smoking, consuming food, or chewing gum for at least $1 / 2 \mathrm{~h}$ prior to testing.

\section{Maferials}

Allyl isothiocyanate and three isonitrile homologs (methyl isonitrile, t-butyl isonitrile, and phenyl isonitrile) were used in the experiments. All three isonitriles were synthesized in the laboratory; purity (in excess of 99\%) was established by means of gas liquid chromatography. To minimize any possible chemical changes, experiments were carried out within $72 \mathrm{~h}$ of the synthesis. When not in use, samples were stored in the cold $\left(2^{\circ} \pm 2^{\circ} \mathrm{C}\right)$.

\section{Stimulus Preparation}

An air-dilution olfactometer was used to present allyl isothiocyanate to the Ss. The apparatus has been described previously (Stone et al, 1967; Stone \& Bosley, 1965). The technique involved introduction of a known amount of odorant for a specified time, following which $S$ indicated its presence or absence.

The "sniff-bottle" method was used to obtain S's response on the isonitriles. The usefulness and the reliability of the method has been discussed elsewhere (Amerine, Pangborn, \& Roessler, 1965; Jones, 1955). The odorants were prepared in small $50 \mathrm{ml}$ centrifuge tubes with aluminum foil covered caps. Each odorant series was obtained by serial dilution with methyl slloxane (Dow Corning No. 200 fluid, $10 \mathrm{CS}$ ) based on a $\log _{10}$ series. In some experiments with methyl isonitrile and t-butyl isonitrile, glassdistilled, charcoal-filtered water was used as the solvent. Each $S$ had three replicate series for each test to minimize any possible errors due to nonequilibrated samples. For methyl isonitrile, nine dilutions were prepared from a stock solution of $1.818 \times 10^{-3} \mathrm{M}$; for $\mathrm{t}$-butyl isonitrile the stock solution was $1.037 \times 10^{-3} \mathrm{M}$; and for phenyl isonitrile, $9.479 \times 10^{-3} \mathrm{M}$.

\section{Test Method}

A forced choice, single sample tracking method was used. The method enables $E$ to track S's responses as the stimulus concentration is varied (Stone et al, 1967). E presents $S$ with a descending series until he no longer perceives the stimulus. At this point $S$ is presented with random test concentrations (in the immediate vicinity where the response was lost). This permits $E$ to establish relatively narrow limits for the detection and recognition thresholds and then to "zero in" on that threshold. A large number of blank samples were also included. This procedure enabled us to obtain a threshold from $S$ in a test period of 10-15 min.

\section{Procedure}

All experiments (except diurnal variation) were carried out between 8:30 AM and $11 \mathrm{AM}$, under carefully controlled conditions. Test room temperature was maintained at $22^{\circ} \pm 2^{\circ} \mathrm{C}$. Odor build-up in the room was minimized by means of an exhaust system to the outside. Ss were tested singly at the same time each test day. S entered the test room, sat down, and received a written set of directions explaining the task. To orient $\mathrm{S}$, he was presented 
Table 1. Median Olfactory Thresholds under Different Experimental Conditions*

\begin{tabular}{|c|c|c|c|c|c|c|}
\hline \multirow{2}{*}{ Odorant } & \multicolumn{4}{|c|}{ Detection } & \multicolumn{2}{|c|}{ Recognition } \\
\hline & Light & Dork & Light & Dark & Light & Dark \\
\hline \multirow{4}{*}{$\begin{array}{l}\text { Methyl } \\
\text { isonitrile }\end{array}$} & $3.63 * *$ & 36.60 & -- & -- & 36.3 & 66.0 \\
\hline & $(.007-6.6)$ & $(.007-66.0)$ & -- & -- & $(6.6-660)$ & $(66.0-120.0)$ \\
\hline & $\begin{array}{c}6.60 \\
(.1168-116.8)\end{array}$ & $\begin{array}{c}9.10 \\
(6.6-66.0)\end{array}$ & $\begin{array}{l}66.0 \\
(6.6-660.0)\end{array}$ & $\begin{array}{l}66.0 \\
(11.68-66.0)\end{array}$ & $\begin{array}{l}-- \\
--\end{array}$ & $\begin{array}{l}-- \\
--\end{array}$ \\
\hline & $\begin{array}{c}.069 * * * \\
(.069-.69)\end{array}$ & $\begin{array}{c}.127 \\
(.069-.69)\end{array}$ & $\begin{array}{l}-- \\
--\end{array}$ & $=$ & $\begin{array}{c}0.69 \\
(.069-1.27)\end{array}$ & $\begin{array}{c}0.69 \\
(.069-1.27)\end{array}$ \\
\hline $\begin{array}{l}\text { t-Butyl } \\
\text { i sonitrile }\end{array}$ & $\begin{array}{c}16.7 * * * \\
(1.67-16.7)\end{array}$ & $\begin{array}{l}16.7 \\
(1.67-16.7)\end{array}$ & $\begin{array}{l}167.0 \\
(1.67-167.0)\end{array}$ & $\begin{array}{l}167.0 \\
(.295-167.0)\end{array}$ & $\begin{array}{l}16.7 \\
(16.7-167.0)\end{array}$ & $\begin{array}{l}16.7 \\
(16.7-167.0)\end{array}$ \\
\hline $\begin{array}{l}\text { Pheny! } \\
\text { isonitrile }\end{array}$ & $\begin{array}{l}110.0 \\
(11.0-1090.0)\end{array}$ & $\begin{array}{l}110.0 \\
(2.0-227.0)\end{array}$ & $\begin{array}{l}599.0 \\
(109.0-1090 .\end{array}$ & $\begin{array}{l}599.0 \\
0)(109.0-1090)\end{array}$ & $\begin{array}{l}1090.0 \\
(109.0-1090)\end{array}$ & $\begin{array}{l}1090.0 \\
(109.0-1090)\end{array}$ \\
\hline
\end{tabular}

* All values are reported as concentration $X 10^{-7} g / l$ in the vapor.

** Each entry is the median of the panel (and range), two threshold values from each of six Ss.

*** These experiments made use of water as the solvent.

with an identified stimulus and a blank. Testing then began and lasted for approximately $1 \mathrm{~h}$. Within this time period it was possible to obtain two thresholds under each of two test conditions.

The experimental design was such that the first threshold was always a baseline value; i.e., each $S$ served as his own control. The detection tests were conducted on separate days from the recognition tests to minimize possible errors due to confusion by the Ss as to their task (Engen, 1960).

For the light-dark experiments, S's baseline threshold was established; a blindfold was then placed over his eyes and the room was darkened. E would place the test sample in S's hand and he would sniff two or three times. S would respond verbally as to the presence or absence of an odor. For the diurnal variation tests, $\mathrm{S}$ returned $12 \mathrm{~h}$ after his morning experiment, and the test sequence was repeated. All recognition threshold experiments were conducted during the day.

Three forms of auditory stress were investigated: battle sounds, battle sounds with a superimposed narration of the battle, and an intermittent auditory signal-a brief burst (1-3 sec) of white noise presented at' random intervals (every 5-8 sec) to either ear. For each condition a 15 to 20 min tape was played to the Ss through binaural earphones.

\section{Treatment of Data}

Since the tracking procedure enabled us to collect numerous responses at or near the $50 \%$ response level, the threshold could be determined simply by referring to the concentration for that particular beaker or the flowmeter settings on the olfactometer. Sniff-bottle data are reported as median scores, and olfactometric data as mean scores.

\section{RESULTS}

In Table 1 are summarized the results of the light-dark, diurnal variation, detection, and recognition threshold experiments. The data for each odorant are the pooled results for the panel, although the different experiments were conducted on separate days.

Observation of individual scores reveals little, if any, change in sensitivity when $S$ was blindfolded.

The data from the diurnal variation experiments indicated that there was a decrease in sensitivity at night which was evident for most Ss and for all three test odorants. This decrease appeared to be about 10-fold, but was less (about 5-fold) for the phenyl isonitrile.

Analysis of variance of the methyl isonitrile data indicated there was a significant difference between Ss $(p<.01)$, time $(p<.01)$, and the $S$ by time interaction term $(p<.01)$. For the $t$-butyl isonitrile, the differences were not significant, while analysis of the phenyl isonitrile data showed only the $\mathrm{S}$ by time interaction term to be significant $(.05>p>.01)$.

Recognition thresholds for most Ss were approximately 10 times detection thresholds, although the changes were not consistent. Some Ss appeared to

Table 2. Mean Detection Thresholds for Allyl Isothiocyanate as Influenced by Auditory Stress

\begin{tabular}{lcc} 
Panel & Rest (control) & Auditory Stress \\
\hline A** & $3.82 \pm 2.84$ & $4.34 \pm 4.05$ \\
B & $30.32 \pm 11.65$ & $33.94 \pm 22.83$ \\
& & 11 \\
A & $3.64 \pm 2.94$ & $1.73 \pm 1.08$ \\
B & $36.50 \pm 27.72$ & $44.62 \pm 30.43$ \\
& & 111 \\
A & $6.48 \pm 3.23$ & $5.11 \pm 3.88$ \\
B*** & $9.73 \pm 3.90$ & $8.75 \pm 5.01$ \\
& & Pooled Results \\
A & $4.65 \pm 3.14$ & $3.72 \pm 3.39$ \\
B & $21.57 \pm 18.57$ & $24.01 \pm 23.76$
\end{tabular}

* I refers to auditory stress of taped battle sounds, $I I$ is battle sounds with narration, and III is a white noise signal.

** $A$ refers to two experienced $S s ; B$ to two naive $s s$, and each entry is the mean of four threshold determinations, $x 10^{-8} \mathrm{~g} / \mathrm{l}, \pm$ standard deviation.

*** In this experiment there were four naive Ss. 
show no difference between detection and recognition, a rather unusual finding in view of Engen's results (1960).

Results of the auditory stress experiments, summarized in Tables 2 and 3 , show that the three conditions had no significant effect according to analysis of variance on odor sensitivity, whether the Ss were experienced or naive.

\section{DISCUSSION}

The use of a blindfold and a darkened room appeared to have no measurable influence on odor discrimination. Initially some Ss showed a slightly decreased sensitivity. However, this proved to be more of a position problem. $S$ would be given the stimulus and, in bringing it to his nose, might misjudge location; this problem was quickly overcome as experiments continued.

The data on recognition thresholds are most interesting from the viewpoint of odor quality. The methyl isonitrile is quite repulsive, and it seemed to the Es that it retained its quality at concentrations that were just detectable (some of our Ss also noted this). This is also true, to a limited extent, for the t-butyl and phenyl isonitriles, which might explain why some Ss showed no difference in the concentrations required for detection or recognition thresholds. However, it is also likely that Ss may have changed their criterion for judgment in spite of the fact that they were all experienced. As Engen (1960) noted, once $S$ was exposed to both techniques, he found it difficult to pay attention only to quality. All of our Ss were establishing detection thresholds before the recognition tests. The unpleasantness of these stimuli also may have contributed to the problem.

The results of the $12 \mathrm{~h}$ diurnal variation experiment are not clear. Since we tested at only one time interval, $12 \mathrm{~h}$, we have no idea as to what changes may have occurred at other times. Our data suggest

Table 3. Median Detection Thresholds for Methyl Isonitrile as Influenced by Auditory Stress

\begin{tabular}{|c|c|c|}
\hline Panel & Rest (control) & Auditory Stress \\
\hline & & $I^{*}$ \\
\hline $\begin{array}{l}A^{* *} \\
B\end{array}$ & $\begin{array}{l}9.54(6.36-12.7)^{* * *} \\
0.954(.636-6.36)\end{array}$ & $\begin{array}{c}63.6(0) \\
6.36(.636-6.36) \\
11\end{array}$ \\
\hline A & $6.36(1.27-63.6)$ & $6.36(6.36-63.6)$ \\
\hline B & $6.36(0)$ & $\begin{array}{r}6.36(0) \\
111\end{array}$ \\
\hline A & $6.36(0)$ & $9.54(6.36-12.72)$ \\
\hline B & \multicolumn{2}{|c|}{ Pooled Results } \\
\hline A & $6.36(1.27-63.6)$ & $9.54(6.36-63.6)$ \\
\hline B & $.954(.127-6.36)$ & $6.36(.636-6.36)$ \\
\hline
\end{tabular}

* I refers to auditory stress of taped battle sounds, II is battle sounds with narration, and III is a white noise signal.

** $A$ refers to two experienced $S s ; B$ to two naive $S s$, and each entry is median of four threshold determinations, $x 10^{-8} \mathrm{~g} / \mathrm{l}$. The naive Ss were different from those used in the allyl isothiocyanate experiment.

*** Entries in parentheses are the range of values. that sensitivity at night decreased approximately 10fold; however, more experimentation is needed to clarify this problem.

The results of the auditory stress experiments were interesting. The battle sound and narration experiments were reported by some Ss to be more distracting than stressful. Ss reported the white noise to be the most annoying; however, none of the stresses affected odor sensitivity.

These results and those reported above for the light/dark experiments were of interest to us from the viewpoint of sensory interactions and their effects on sensitivity. Since our studies were not concerned directly with sensory interactions, we hesitate to speculate on the implications of the data reported herein. Rather, we emphasize the need for more study on sensory interaction utilizing the olfactory system of man.

The use of water instead of methyl siloxane as the solvent (Table 1) appeared to cause a change in the threshold, which we attribute to deviations from ideality (Stone, 1963). Quantitative gas chromatographic analysis of the vapor phase above the aqueous solutions revealed that ideality was approached at concentrations below $10^{-6} \mathrm{~g} / \mathrm{liter}$. Therefore, the absolute values reported for the third methyl isonitrile and the t-butyl isonitrile experiments are correct. Concentrations above $10^{-6} \mathrm{~g} / \mathrm{liter}$ were found to be less than calculated from ideality. Experiments involving methyl siloxane solutions were inconclusive; however, the data suggest that vapor phase concentrations show greater deviations from ideality, likely due to the greater viscosity of the siloxane.

The experiments described here lend additional support to our hypothesis that the olfactory system of man is capable of functioning under a variety of physiological, behavioral, and environmental conditions with minimal changes in sensitivity (Stone et al, 1967). We are continuing these investigations.

\section{References}

Amerine, M. A., Pangborn, R. M., \& Roessler, E. B. Principles of sensory evaluation of food. New York: Academic Press, 1965.

Engen, T. Effect of practice and instruction on olfactory thresholds. Percept. mot. Skills, 1960, 10, 195-198.

Jones, F. N. The reliability of olfactory thresholds obtained by sniffing. Amer. J. Psychol., 1955, 68, 289-290.

Stone, H. Techniques for odor measurement: Olfactometric vs sniffing. J. Food Sci., 1963, 28, 719-725.

Stone, H., \& Bosley, J. J. Olfactory discrimination and Weber's Law. Percept. mot. Skills, 1965, 20, 657-665.

Stone, H., Pryor, G., \& Colwell, J. Olfactory detection thresholds in man under conditions of rest and exercise. Percept. \& Psychophys., 1967, 2, 167-170.

\section{Note}

1. This research was supported by Edgewood Arsenal, Edgewood Arsenal, Maryland under Contract DA 18-035-AMC-738(A) with Stanford Research Institute. The authors extend grateful appreciation to Mr. Robert Dehn for synthesis and purification of the odorants, to Mrs. J. Colwell and Mrs. S. Oliver for technical assistance, and to the panel for their cooperation.

(Accepted for publication July 3, 1967.) 